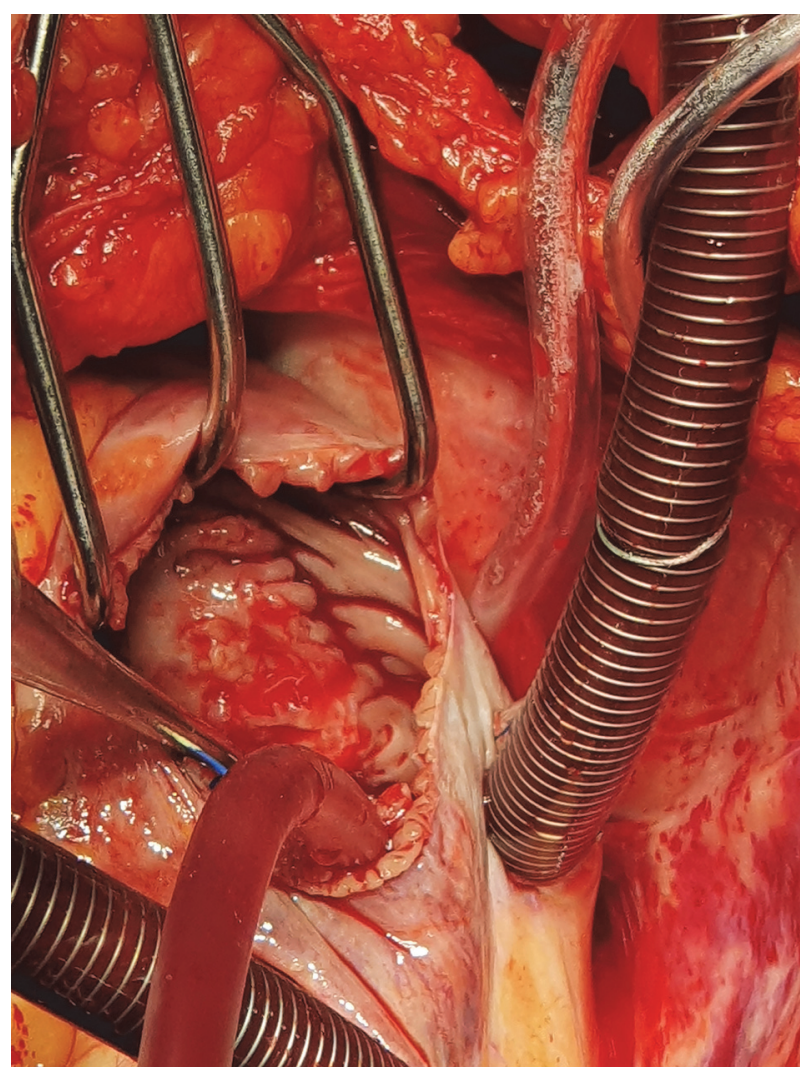

Abstract 1089 Figure 2

cardiac surgeons, pathologists, oncologists and cardiovascular anesthesiologists were involved. A complete trans-thoracic echocardiogram was performed, showing an isoechoic, mobile, adherent to the tricuspid ring, 22 x $50 \mathrm{~mm}$ mass with nonsmooth margins, resulting in obstruction of the right ventricular filling (gradient $7 \mathrm{mmHg}$ ). Cardiac magnetic resonance imaging (MRI) demonstrated a 41x35 mm, polylobed mass, adhered to the tricuspid ring on the inferior-posterior side, which incorporated the posterior and septal flaps of the tricuspid valve, extensively emerging in the ventricular cavity in the diastolic phase. The mass obstructed the right ventricular filling and its most caudal portion partially occupied, in the systolic phase, the outlet of the inferior vena cava in the atrium. Because of the life-threatening obstruction, the mass was removed by cardiac surgeons with sternotomy in extracorporeal circulation. During surgery, the mass was analyzed by pathologist, confirming the endometrial origin. Postoperatively, radiotherapy (RT) on the heart was performed, followed by second line CHT with Liposomal Doxorubicin till February 2021.

Result(s)* In February 2021 cardiac MRI was performed, showing no evidence of disease. Complete response of the oropharyngeal and abdominal recurrences was also detected. But the woman presented with neurological symptoms, as partial paralysis of the legs. Encephalic MRI was performed showing brain metastases. The woman underwent pan-encephalic RT with subsequent reduction of those lesions.

In June 2021, the woman is still alive without neurological nor other symptoms.

Conclusion* A multidisciplinary approach is essential to treat rare EC metastases. Reference centers for the treatment of EC must have specialists from other disciplines available, to ensure the best clinical practice.

\section{OPTIMISING OUTCOMES FOR LAPAROSCOPIC HYSTERECTOMY IN PATIENTS WITH MORBID OBESITY}

E Van der Zanden, F Testa, C White, P Larsen-Disney, F Drews, S Kaushik, S Baron* University Hospitals Sussex NHS Foundation Trust, Gynaecological Oncology, UK

\subsection{6/ijgc-2021-ESG0.229}

Introduction/Background* Operating on patients with a significantly raised body mass index (BMI) represents a significant challenge to the surgical and the anaesthetic team. Hysterectomy for early-stage uterine cancer is usually performed via laparoscopy.

We aimed to evaluate whether a two consultant 'buddy operating' approach improves on intra-operative and postoperative outcomes in patients undergoing total laparoscopic hysterectomy (TLH) for endometrial cancer who are morbidly obese.

Methodology A prospectively selected cohort of 25 patients with a BMI 47-70 undergoing TLH was divided into two groups according to whether the first assistant to the GynaeOncology consultant was a registrar (ST3-7), or a consultant ('buddy operating'). Anaesthetic time, operating time, intraoperative estimated blood loss (EBL), requirement for high dependency unit (HDU) bed and length of stay (LOS) were compared in the two groups.

Result(s)* Average 'buddy' operating time was significantly shorter compared to the registrar-assistant group $(01: 31 \mathrm{~h}$ vs $01: 59$ h respectively; $\mathrm{p}<0.001)$; a similar trend was seen with the average total anaesthetic time $(02: 48 \mathrm{~h}$ vs $03: 23 \mathrm{~h}$ respectively; $\mathrm{p}<0.001)$. EBL was less in the 'buddy operating' group $(39 \mathrm{mls})$ vs registrar-assistant group $(169 \mathrm{mls}$; $\mathrm{p}<0.001)$. Postoperatively, LOS was shorter in the 'buddy operating' group as compared to the registrar-assistant, though not significantly so $(1.13$ vs 1.59 days; $p=0.109) .2$ of the total patients $(8 \%)$ required a one-night stay in HDU for observation due to their co-morbidities, both in the registrar-assistant group. Mean BMI, age, ASA and comorbidities were similar in the two groups.

Conclusion* In patients with a significantly raised BMI, TLHs by two consultants vs consultant and registrar are associated with better intra and post-operative outcomes, including reduced overall anaesthetic time, operating time, and EBL. There is an association with a reduced length of overall hospital stay, though this was not significant.

\section{IMPLICATIONS OF OBESITY IN ENDOMETRIAL CANCER}

${ }^{1 ; 2} \mathrm{MC}$ Tirnovanu*, ${ }^{3 ; 4} \mathrm{D}$ Timofte, ${ }^{5} \mathrm{R}$ Corduneanu, ${ }^{5} \mathrm{~A}$ Crudu, ${ }^{5} \mathrm{~B}$ Scurtu, ${ }^{6} \mathrm{~A}$ lov, ${ }^{7} V G$ Tîrnovanu. 'University of Medicine and Pharmacy "Gr T Popa', Obstetrics and Gynecology, lasi, Romania; '2Clinical Hospital of Obstetrics and Gynecology „,Cuza Vodă', lasi, Romania; 'University of Medicine and Pharmacy "Gr T Popa', Surgery, lasi, Romania; ${ }^{4}$ Clinical Hospital "Sfântul Spiridon' laşi, Surgery, lasi, Romania; ${ }^{5}$ Clinical Hospital of Obstetrics and Gynecology "Cuza Vodă', Obstetrics and Gynecology, lasi, Romania; ${ }^{6}$ University of Medicine and Pharmacy "Gr T Popa', student sixth year, lasi, Romania; 'University of Medicine and Pharmacy ",Gr T Popa', student fourth year, lasi, Romania

\subsection{6/ijgc-2021-ESG0.230}

Introduction/Background* Over half of the endometrial cancers (EC) are caused by obesity, known as an independent risk factor. In Romania, in the last years the obesity rate had an alarming growth, with many high grade cases that influence the clinical management of the disease, the surgical procedure, radiotherapy planning, and the survival rate. 
Objective: To establish the obesity incidence according to BMI (body mass index) in 1st Department of Gynecology Iasi and to correlate the grade of obesity with prognostic factors. We also looked at the challenges of treating EC caused by obesity.

Methodology It was a prospective study on 110 pacients with surgical treatment for EC from the $1^{\text {st }}$ Clinic of Gynecology Iasi between January 2014-June 2021. We evaluated the BMI of the patients defined by WHO. For 15 women we made correlation between others parameters for assessing obesity and aggressiveness of EC.

Result(s)* The mean age of the patients was 60.15 years (limits $36-87$ years). $83.33 \%$ of the cases were diagnosed with stage I cancer. 54 women were obese. Most of them associated hypertension with obesity-36, 27 cases had diabetes with obesity and only 25 women presented the classic triad hypertension-diabetes-obesity. We didn't find statistic correlation between obesity rate and disease stage $(p=0.427)$, tumor grading $(\mathrm{p}=0.690)$ or vascular invasion $(\mathrm{p}=0.84) .5$ patients presented wound infection, 3 had dehiscent scar.

Conclusion* Obesity is involved in disease pathogeny but cancer aggressiveness is not correlated with the grade of it. The association between obesity and hypertension determines a more advanced stage of disease and increases the grading. The classical risk triad was not statistically influenced the stage $\mathrm{p}=0.580$ and grading $\mathrm{p}=0.098$. Weight loss after surgery is a priority for decreasing the rate of recurrence, but in our country few patients understand the importance of this goal.

\section{ENDOMETRIAL CANCER IN A DEVELOPING COUNTRY; EMERGING TREND}

${ }^{1} \mathrm{M}$ Umemmuo*, 'E Oladunni, ${ }^{2} \mathrm{~F}$ Igbinoba. 'National Hospital Abuja, Department of Obstetrics and Gynaecology, Abuja, Nigeria; ${ }^{2}$ National Hospital Abuja, Department of oncology, Abuja, Nigeria

\subsection{6/ijgc-2021-ESG0.231}

Introduction/Background* Cancer of the uterine corpus is the most common pelvic gynecologic malignancy in developed countries and has been reported to be on the increase in developed countries. However, there is a paucity of data on the trend of endometrial cancer in developing countries.

Methodology A 10-year review of endometrial malignancies (2011-2020) at a tertiary institution in Nigeria. Data on endometrial cancer were generated using a cancer registry (ICD-10 CanReg5 software). There were 93 endometrial malignancies during the period and data was analyzed using SPSS version 22

Result(s)* A total of $93(100 \%)$ were analyzed. Most of the patients had tertiary education $51 \quad(56.7 \%$ 54.8\%). The peak age range was 60-69years (34\%) followed by 50-59years (26\%). However, $5(5.4 \%)$ cases recorded were below the age of 40years. Approximately $65(69.9 \%)$ cases of endometrial carcinomas were endometrioid adenocarcinomas. Other histologic subtypes include; adenosquamous 11 (11.8\%), Papillary $8(8.6 \%)$ sarcomas $7(7.5 \%)$, and 1 (1.1\%) for clear cell type, and mixed Mullerian tumour respectively. The histological forms of the five $(5.4 \%)$ recorded in under 40years patients were endometrioid adenocarcinoma $3(60 \%)$ and adenosquamous $2(40 \%)$. There was a sustained rise in the prevalence of endometrial cancer from 4 (4.3\%) in 2016 to 21 (22.6\%) in 2018 with a slight decline to 18 (19.4\%) in 2019.
Abstract 1134 Table 1 showing the number of cases for different age groups over the 10 years' period

\begin{tabular}{llllllll}
\hline $\begin{array}{l}\text { YEAR/AGE } \\
\text { GROUP }\end{array}$ & $30-$ & $40-$ & $50-$ & $60-$ & $\begin{array}{l}70- \\
79\end{array}$ & $\begin{array}{l}80 \\
+\end{array}$ \\
\hline 2011 & 39 & 49 & 59 & 69 & 79 & \\
2012 & 0 & 0 & 2 & 2 & 0 & 0 & 4 \\
2013 & 0 & 1 & 3 & 1 & 1 & 2 & 8 \\
2014 & 0 & 1 & 1 & 3 & 0 & 2 & 7 \\
2015 & 0 & 2 & 0 & 2 & 1 & 0 & 5 \\
2016 & 0 & 2 & 4 & 1 & 1 & 0 & 8 \\
2017 & 0 & 1 & 1 & 1 & 1 & 0 & 4 \\
2018 & 2 & 0 & 4 & 3 & 1 & 1 & 11 \\
2019 & 3 & 2 & 4 & 10 & 2 & 0 & 21 \\
2020 & 0 & 2 & 6 & 7 & 2 & 1 & 18 \\
TOTAL & 0 & 2 & 1 & 4 & 0 & 0 & 7 \\
\hline
\end{tabular}

\section{TREND OF ENDOMETRIAL CA FROM 2011-2020}

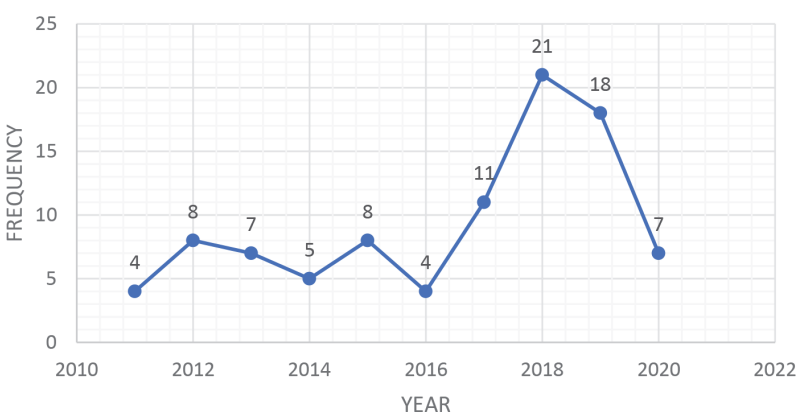

Abstract 1134 Figure 1 Trend of endometrial CA from 2011-2020

However, in 2020 a sharp decline was recorded. The occurrence of endometrial cancer in the younger age group (below 40 years) was recorded during the period of the sudden rise in the prevalence of endometrial cancer.

Conclusion* Given the increasing prevalence of endometrial cancer in our setting, there is a need for lifestyle modifications and increase awareness of endometrial cancer. More research efforts and aids are needed in other to curb the increasing trend of this problem in developing countries.

\section{A PILOT STUDY FOR THE VALIDATION OF SENTINEL LYMPH NODE BIOPSY WITH FLUORESCENCE METHOD IN EARLY ENDOMETRIAL CANCER}

J García Villayzan*, M Albi Gonzalez, J Utrilla -Layna. Madrid, Madrid, Spain

\subsection{6/ijgc-2021-ESG0.232}

Introduction/Background* Sentinel Lymph Node Biopsy is a technique developed to predict lymphatic involvement in patients with early endometrial cancer, decreasing the morbimortality associated with routine systematic lymphadenectomy and improving quality of life.

Methodology

Main Objective To determine the detection rate and negative predictive value of the Sentinel Lymph Node Biopsy by Immunofluorescence in patients with early endometrial cancer. Method A descriptive observational study in patients with early endometrial cancer (FIGO stage I-II) for all histological 